\title{
Envelhecimento Populacional no Conselho Regional de Desenvolvimento do Litoral/RS e as implicações para as políticas públicas
}

\author{
Rossandra Oliveira Maciel de Bitencourt ${ }^{1}$ \\ Fabiano Abranches Silva Dalto ${ }^{2}$
}

\begin{abstract}
RESUMO
O objetivo geral deste trabalho consiste em analisar o processo de envelhecimento populacional nos municípios do Conselho Regional de Desenvolvimento do Litoral e seu potencial impacto sobre as políticas necessárias para o atendimento das demandas desse segmento. A metodologia utilizada foi um levantamento de dados junto ao Instituto Brasileiro de Geografia e Estatística (IBGE) e ao Programa das Nações Unidas para o Desenvolvimento (PNUD). A abordagem de análise foi quantitativa. No que se refere aos resultados, constatou-se inicialmente que no período de 2000-2010 esta foi a região do estado com maior destaque no aumento populacional. Com relação à população acima de 60 anos, este aumento foi de $75 \%$ superando as médias estadual e nacional. Por um lado, tem-se o aumento da população idosa nos balneários com pessoas provenientes de regiões metropolitanas do estado, que após a aposentadoria buscam um lugar tranquilo que propicie lazer e maior qualidade de vida. Por outro lado, nos municípios rurais verifica-se os fenômenos do êxodo juvenil, da masculinização e do envelhecimento do campo. Ou seja, embora os balneários apresentem expressivo aumento da população idosa por atrair aposentados, os municípios rurais destacam-se pelo intenso processo de envelhecimento daqueles que permanecem no campo. Em suma, os municípios precisam estar empenhados em atender as deliberações da Política Nacional do Idoso no que se refere à garantia de direitos e à inserção dos idosos no espaço público enquanto sujeitos sociais e coletivos. Os resultados desta pesquisa evidenciam que a população idosa do COREDE Litoral apresenta demandas segundo as especificidades de cada município, o que requer cautela na implementação de políticas públicas, pois estas não podem ser racionalmente planejadas para uma determinada categoria, englobando um universo de indivíduos que na prática não são homogêneos.
\end{abstract}

Palavras-chave: Corede Litoral, Envelhecimento Populacional, Políticas Públicas

\section{INTRODUÇÃO}

Segundo dados do Instituto Brasileiro de Geografia e Estatística - IBGE, a população residente no Brasil com idade superior a 60 anos aumentou $42 \%$ no período de 2000 a 2010. Tal aumento tem exigido dos formuladores de políticas públicas um novo olhar frente a esta população. Dentre os avanços conquistados pela geração idosa no Brasil, destacase a implementação da Lei 8.842 de 1994 que institui a Política Nacional do Idoso e cria o Conselho Nacional do Idoso. Essa foi uma conquista fundamental para os idosos, pois ao assegurar-lhes uma série de direitos a referida lei contribui em diversos aspectos para a sua

\footnotetext{
${ }^{1}$ Economista. Mestra e Doutoranda em Políticas Públicas pela Universidade Federal do Paraná (UFPR). É membro da diretoria da Associação dos Pesquisadores em Economia Catarinense (APEC). Integra o Núcleo de Estudos em Instituições (UFPR). Email: rossandra.maciel@yahoo.com.br

${ }^{2}$ Economista. Mestre em Desenvolvimento Econômico e Doutor em Economia Institucional pela Universidade de Hertfordshire, Inglaterra. Professor da Universidade Federal do Paraná (UFPR). Email: dalto@ufpr.br.
} 
valorização e reafirmação em meio à sociedade, seja através das atribuições à saúde, como pelas referências de direito ao lazer, à cultura e à qualidade de vida.

De modo a complementar a Política Nacional do Idoso, foi aprovado no Brasil em setembro de 2003, através do Projeto de Lei n 3.561/1997, o Estatuto do Idoso. Conforme destaca Silva (2005) é comum a criação de estatutos em países onde os direitos sociais não são totalmente respeitados. Neste âmbito o Estatuto do Idoso, que dispõe de 118 artigos, emergiu com a finalidade de assegurar a garantia de diversos direitos às pessoas idosas.

No contexto internacional a geração idosa também ganhou espaço através da I Assembleia Mundial sobre Envelhecimento que ocorreu em 1982 em Viena; e da II Assembleia Mundial sobre Envelhecimento que ocorreu no ano de 2002 em Madrid. Nesta mais recente, frisou-se que o envelhecimento ao invés de ser percebido como um problema é antes uma conquista para a sociedade, o que constitui a razão de se promover uma visão positiva da geração idosa. Na última assembleia destacou-se ainda que o envelhecimento deve ocupar um lugar fundamental em todas as prioridades no domínio do desenvolvimento, garantindo sua participação ativa na vida econômica, social, cultural e política.

Contudo, no âmbito acadêmico, o idoso ainda sofre uma determinada negligência, de modo que grande parte das pesquisas realizadas com esta geração está relacionada às doenças que emergem nesta fase da vida. Na área das ciências sociais, segundo Motta (2010), muitas vezes o idoso é visto como um problema social que precisa ser superado, sobretudo nesta sociedade, em que a juventude foi eleita como modelo cultural a ser seguido. A autora acrescenta que esta negligência está associada ao declínio da vitalidade, pois apesar da aposentadoria se constituir em um direito reconhecido, o aposentado é visto como um ser que não tem mais serventia para o trabalho. Ademais, esta relação entre idoso e improdutividade leva à falácia comum de que "lugar de velho é em casa", o que remete à necessidade de pensar a questão da velhice para além da esfera privada, identificando e avaliando as ações e políticas que contribuem para sua inserção no espaço público.

Neste contexto, busca-se investigar o processo de envelhecimento populacional nos municípios do Conselho Regional de Desenvolvimento (Corede) do Litoral/RS atentando para as especificidades de cada localidade a fim de contribuir para reflexão sobre as políticas públicas diante dos fluxos migratórios dos idosos. Segundo o último censo do IBGE, o estado do Rio Grande do Sul possui 497 municípios que estão divididos em 28 Conselhos Regionais de Desenvolvimento (COREDEs). A escolha da região do COREDE Litoral para presente pesquisa deriva do aumento considerável de sua população acima de 60 anos no período de 
2000 a 2010 cujo dado foi de $75 \%$, aumento este superior a todos os demais COREDEs, e à média nacional, que foi de $42 \%$ para o referido período. Há duas questões que explicam esse aumento considerável, uma delas é o fato de a região possuir alguns balneários, que se constituem em pontos atrativos para os idosos, pois após a aposentadoria muitos migram para o litoral em busca de maior qualidade de vida. A outra explicação está na alta concentração da população idosa residente em pequenos municípios rurais pertencentes ao COREDE Litoral.

No tocante a metodologia, realizou-se um levantamento de dados abrangendo variáveis demográficas dos municípios que contemplam a região. Tais informações foram coletadas através do Censo do Instituto Brasileiro de Geografia e Estatística (IBGE) e do Programa das Nações Unidas para o Desenvolvimento (PNUD) com abordagem de análise foi quantitativa.

O presente artigo está dividido em quatro partes. Após esta breve introdução, a seguir aborda-se algumas considerações sobre o processo de envelhecimento no Brasil. $\mathrm{Na}$ sequência estão os resultados desta pesquisa, e por fim encontram-se as considerações finais acerca do que foi observado.

\section{CONSIDERAÇÕES SOBRE O PROCESSO DE ENVELHECIMENTO NO BRASIL}

Já é evidente que há um aumento considerável na proporção de idosos com relação à população total em praticamente todos os lugares do mundo. Segundo a ONU (2015) no período entre 2015 e 2030, o número de pessoas no mundo com 60 anos ou mais está projetado para crescer em 56\%, de 901 a 1400 milhões. Contudo, embora o envelhecimento da população seja um fenômeno mundial, o processo de envelhecimento é mais avançado em algumas regiões do que em outras, tendo começado há mais de um século atrás em países que se desenvolveram mais cedo. Já nos países em desenvolvimento, considera-se o processo de envelhecimento algo recente, devido ao declínio das taxas de fecundidade que se deu mais tardiamente.

Consequentemente, hoje os países em desenvolvimento têm de se adaptar muito mais rapidamente ao envelhecimento da população a níveis mais baixos de renda nacional em comparação com a experiência de países que se desenvolveram mais cedo. A ONU (2015) também destaca que o número de pessoas idosas nas regiões menos desenvolvidas aumentou $60 \%$ de 2000 a 2015. E prevê-se um crescimento de $71 \%$ entre 2015 e 2030. 
Em meio a este aumento da população idosa, no Brasil Camarano et al. (2004) revelam que o envelhecimento da população não se restringe apenas ao contingente de pessoas que alcança os 60 anos. Mas destacam que há um aumento na proporção da população "mais idosa", a de 80 anos e mais, alterando a composição etária dentro do próprio grupo. Logo, é possível afirmar que a população considerada idosa também está envelhecendo.

Neste aspecto a ONU (2015) salienta que, globalmente, o número de pessoas com 80 anos ou mais está crescendo ainda mais rápido que o número de pessoas idosas em geral. Já no que tange à feminização do envelhecimento, em 2015 as mulheres representavam 54\% da população global de 60 anos ou mais e $61 \%$ das pessoas acima de 80 anos.

É este movimento de envelhecimento que leva ao estreitamento da base e alargamento do topo da pirâmide demográfica. Camarano et al. (2004) afirmam que tais alterações levam a uma heterogeneidade do segmento populacional que extrapola a da composição etária - dadas as diferentes trajetórias de vida experimentadas pelos idosos. Pois um mesmo grupo etário abrange um intervalo de aproximadamente 30 anos: com pessoas na faixa de 60 anos, que, pelos avanços tecnológicos da medicina, podem estar em pleno vigor físico e mental; bem como pessoas na faixa de 90 anos, que devem se encontrar em situações de maior vulnerabilidade.

Em suma, o processo de envelhecimento que se intensifica deve-se fundamentalmente ao aumento da esperança de vida ao nascer, permitindo que mais pessoas atinjam idades avançadas. Conforme destaca Camarano et al. (2004), esse foi o resultado do "sucesso" de políticas econômicas e sociais que resultaram em uma melhoria generalizada das condições de vida, em geral, e de saúde, em particular. No caso da população brasileira, temse observado desde a segunda metade dos anos 1950, embora de forma desigual, maior acesso a serviços médicos preventivos e curativos, a tecnologia médica avançada, a água tratada, a esgoto e saneamento, a escolaridade dentre outros.

Esse conjunto de medidas leva a inferir que o século XXI testemunhará um envelhecimento mais rápido do que o ocorrido no século passado. Conforme destaca Motta (1999), os idosos estão socialmente mais visíveis no cotidiano e no espaço público. Sobretudo, como resposta existencial geracional à própria dinâmica da sociedade contemporânea. Segundo Siqueira et.al (2002), este processo de envelhecimento demográfico, que repercute nas diferentes esferas da estrutura social, denota demandas específicas que se adequem às condições de vida dos idosos. Logo, o desafio é garantir que os indivíduos 
possam envelhecer com segurança e dignidade, mantendo sua participação ativa na sociedade, e que as relações entre as gerações sejam constantemente estimuladas.

Após estas breves considerações sobre o processo de envelhecimento no Brasil, a seguir adentra-se aos resultados da presente pesquisa.

\section{UNIVERSO ANALÍTICO: CONSELHO REGIONAL DE DESENVOLVIMENTO DO LITORAL/RS}

O Conselho Regional de Desenvolvimento (COREDE) Litoral, foi criado em 1991 e atualmente é composto por 21 municípios: Arroio do Sal, Balneário Pinhal, Capão da Canoa, Capivari do Sul, Caraá, Cidreira, Dom Pedro de Alcântara, Imbé, Itati, Mampituba, Maquiné, Morrinhos do Sul, Mostardas, Osório, Palmares do Sul, Terra de Areia, Torres, Tramandaí, Três Cachoeiras, Três Forquilhas e Xangri-lá.

Figura 1 - Municípios pertencentes ao COREDE Litoral - RS

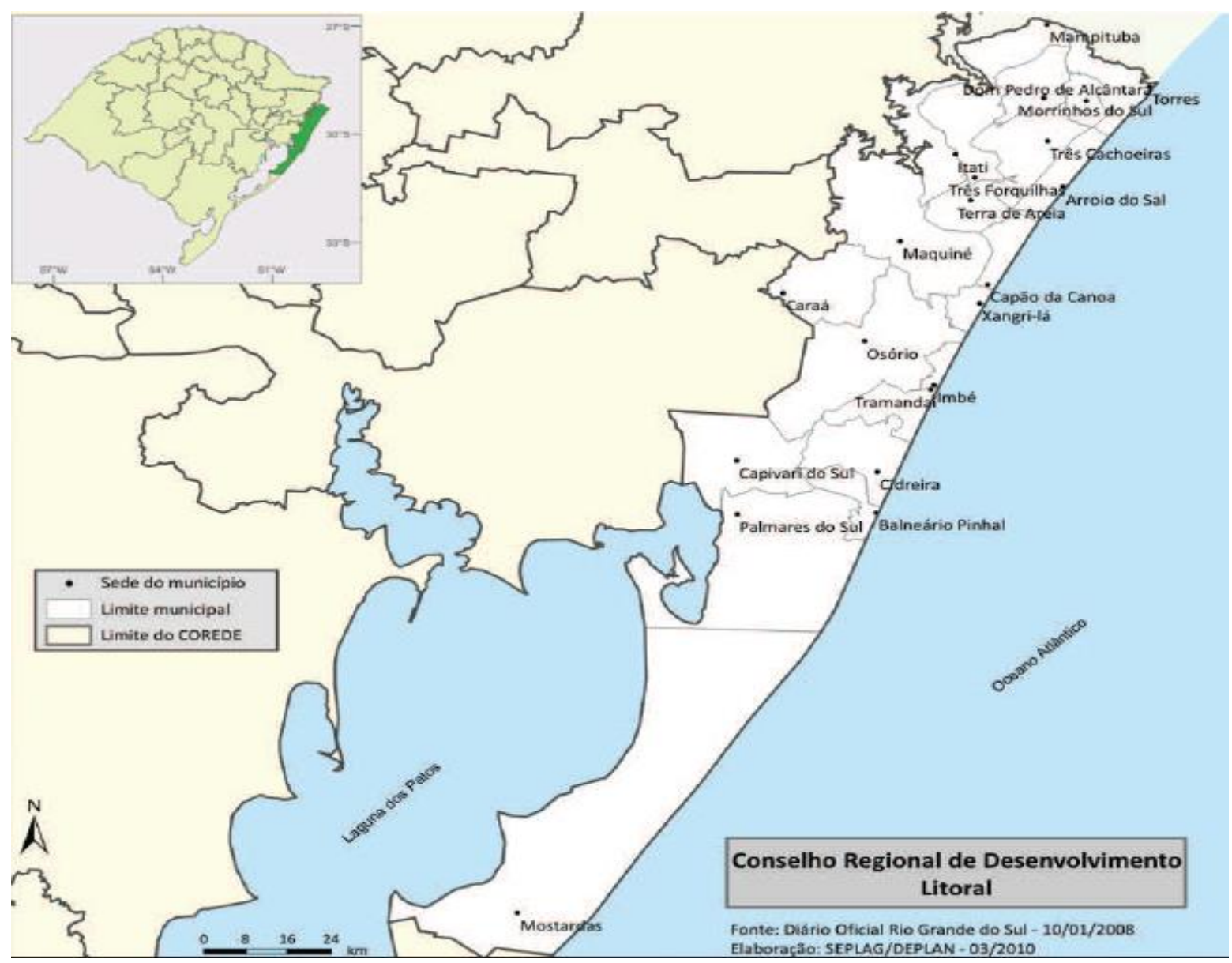

Fonte: COREDE Litoral (2015) 
A seguir são apresentadas informações referentes à dinâmica populacional dos municípios pertencentes ao COREDE Litoral. Essas são fornecidas pelo Censo do IBGE de 2000 e 2010 e pelo Programa das Nações Unidas para o Desenvolvimento (PNUD).

\subsection{Dinâmica Populacional no COREDE Litoral}

O conjunto de políticas para idosos que tem sido estabelecido tanto por órgãos internacionais quanto pelas conquistas democráticas nacionais desde a Constituição de 1988 respondem ao crescimento da população idosa na população geral. Além da maior longevidade da população resultante do desenvolvimento da medicina, a população idosa em determinada região pode se modificar pelos fluxos migratórios. Assim, especificidades da dinâmica populacional de certas regiões podem representar desafios no planejamento da oferta de políticas para uma população cuja dinâmica se altera com certa velocidade.

Segundo a Fundação de Economia e Estatística, em 2016, o COREDE Litoral possuía uma população de 334.107 habitantes. Os municípios mais populosos são Capão da Canoa, Tramandaí e Osório apresentando em torno de 40 mil habitantes. Em segundo plano, aparecem Torres, com 34.656 habitantes, e um grupo formado por Imbé, Cidreira, Xangri-lá, Mostardas, Palmares do Sul, Balneário Pinhal e Três Cachoeiras, com populações entre 10 e 20 mil habitantes. Os demais são de menor porte, com populações abaixo de 10 mil habitantes. Esse COREDE apresenta a particularidade de que os municípios localizados próximos ao litoral, devido à procura pelo turismo de lazer, recebem um fluxo intenso de veranistas, ocasionando um aumento substancial da população, chegando a cerca de 1.000 .000 de habitantes entre os meses de dezembro a março (COREDE LITORAL, 2015).

No período de 2000-2010, com um aumento de 22\%, o COREDE Litoral foi a região que apresentou o maior crescimento populacional do estado do Rio Grande do Sul. E quando se analisa somente a população acima de 60 anos, verifica-se um aumento de $75 \%$, também superior a todos os demais COREDEs, e à média nacional, que foi de $42 \%$ para o referido período. Conforme revela o último censo, há um total de 42.039 pessoas acima de 60 anos de idade residindo nos 21 municípios pertencentes ao COREDE Litoral. Vale ressaltar que o Rio Grande do Sul possui a menor taxa de fecundidade entre os estados brasileiros e a quarta maior expectativa de vida do Brasil. A seguir o Gráfico 1 apresenta a população idosa residente nos municípios do COREDE Litoral/RS: 


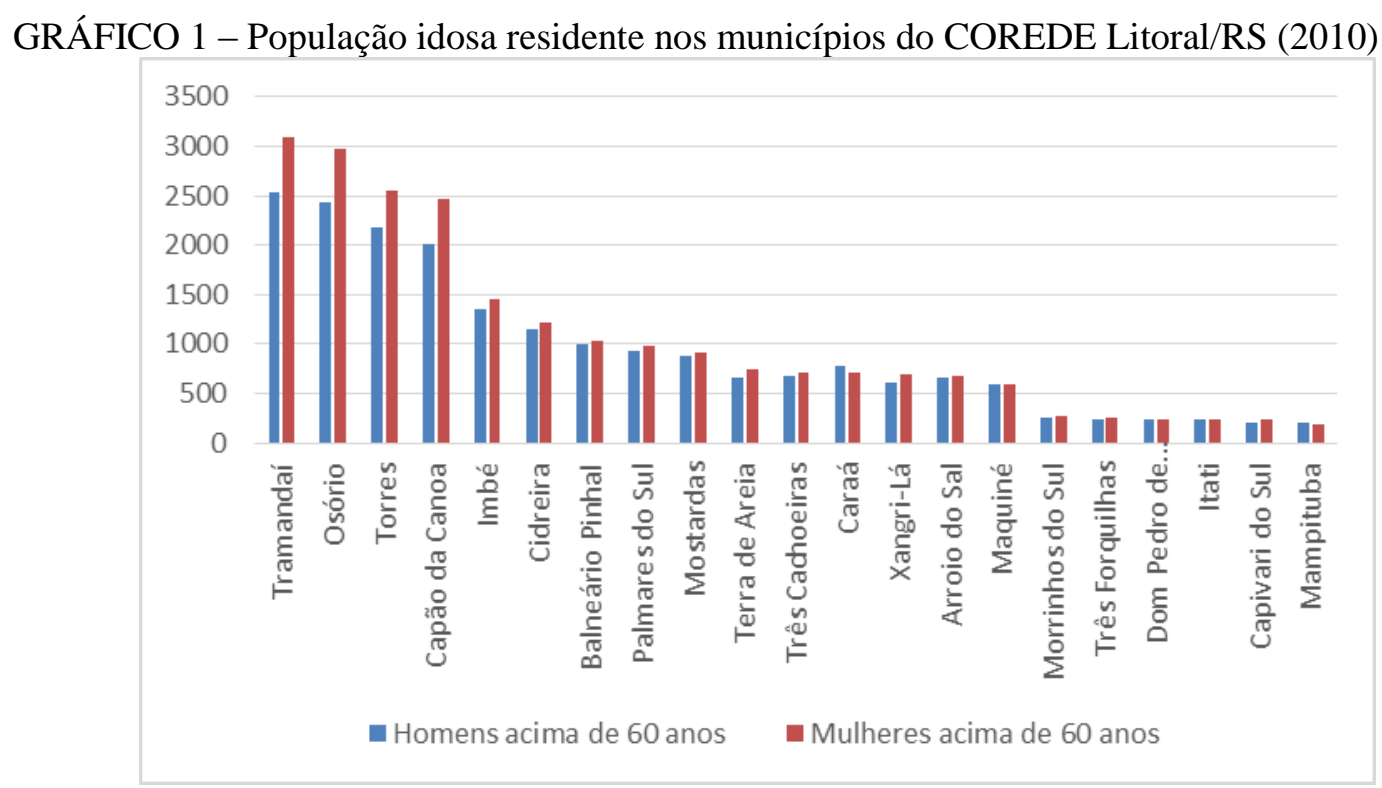

Fonte: IBGE, Elaboração própria

Conforme revela o Gráfico 1, dentre os municípios que apresentam a maior população idosa está Tramandaí com cerca de 5600 idosos, Osório com aproximadamente 5400, seguido por Torres com 4729 e Capão da Canoa com 4475 idosos. Na maioria dos municípios há mais mulheres idosas dos que homens acompanhando a tendência nacional, com exceção dos municípios de Caraá e Mampituba.

Isso se justifica pelo fato de estes serem municípios rurais, onde se verifica o fenômeno da masculinização do campo, também identificado por Froehlich et al (2011) em um estudo efetuado em municípios do Rio Grande do Sul, e por Maciel (2013) na Associação dos Municípios da Região Carbonífera (AMREC)/SC.

Observando o Gráfico 2 é possível analisar os municípios que apresentaram aumento da população idosa com base nos Censos de 2000 e 2010. Verifica-se que Balneário Pinhal, Xangrilá, Imbé, Arroio do Sal, Cidreira, Capão da Canoa e Tramandaí respectivamente foram os municípios que mais atraíram idosos, haja vista que dobraram a população acima de 60 anos para o referido período.

Por outro lado, Três Cachoeiras, Dom Pedro de Alcântara, Mostardas, Morrinhos do Sul, Mampituba, Maquiné, Três Forquilhas e Palmares do Sul foram os municípios que apresentaram menor crescimento, seguidos por Terra de Areia e Caraá que tiveram redução na população idosa de respectivamente $1 \%$ e $28 \%$. 
GRÁFICO 2 - Percentual da população idosa (2000/2010)



Fonte: IBGE, Elaboração própria

Este contraponto se dá pelas especificidades de cada município: aqueles que apresentaram aumentos substanciais da população idosa são os balneários que oferecem praias, lazer e, portanto, mais opções de turismo, tornando-se espaços atrativos para idosos que alcançaram a aposentadoria e buscam um lugar tranquilo para morar nesta fase da vida. Por outro lado, os municípios que apresentaram menor crescimento e até redução da população idosa partilham da semelhança de serem em sua maioria rurais. Conforme demonstra o Gráfico 3, os municípios que possuem a maior população rural $^{3}$ são: Itati com $92 \%$ dos habitantes residindo no campo, seguido por Três Forquilhas com 87\%, Caraá com 86\%, Mampituba com 81\%, Dom Pedro de Alcântara com 71\%, Maquiné com 70\% e Morrinho do Sul com 59\%.

GRÁFICO 3 - Percentual da população rural/total(2010)

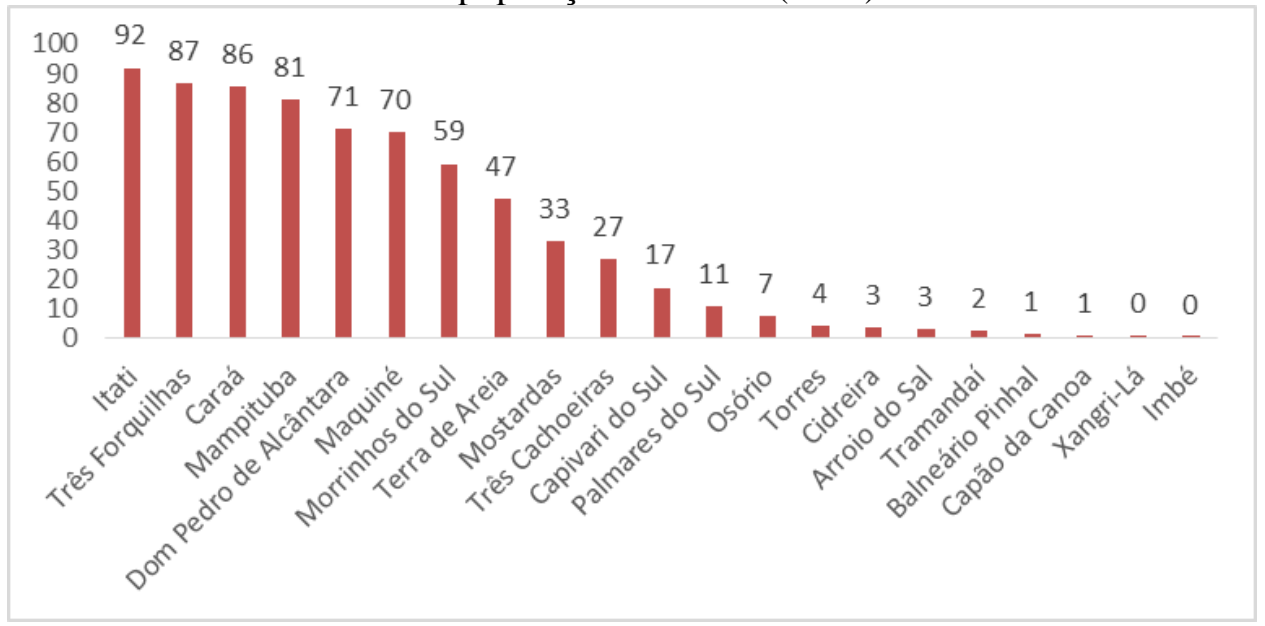

Fonte: IBGE, Elaboração própria

\footnotetext{
${ }^{3}$ A classificação da situação do domicílio é urbana ou rural segundo sua localização, e tem por base a legislação vigente por ocasião da realização do Censo Demográfico 1991. Como situação urbana o IBGE considera as áreas correspondentes às cidades (sedes municipais), às vilas (sedes distritais) ou às áreas urbanas isoladas. A situação rural abrange toda a área situada fora desses limites.
} 
Ou seja, embora os balneários apresentem um expressivo aumento da população idosa, os municípios rurais destacam-se pelo intenso processo de envelhecimento, uma vez que grande parte dos seus habitantes são pessoas acima de 60 anos. A exemplo do município de Caraá, onde mais de $20 \%$ da sua população é idosa, conforme demonstra o Gráfico 4:

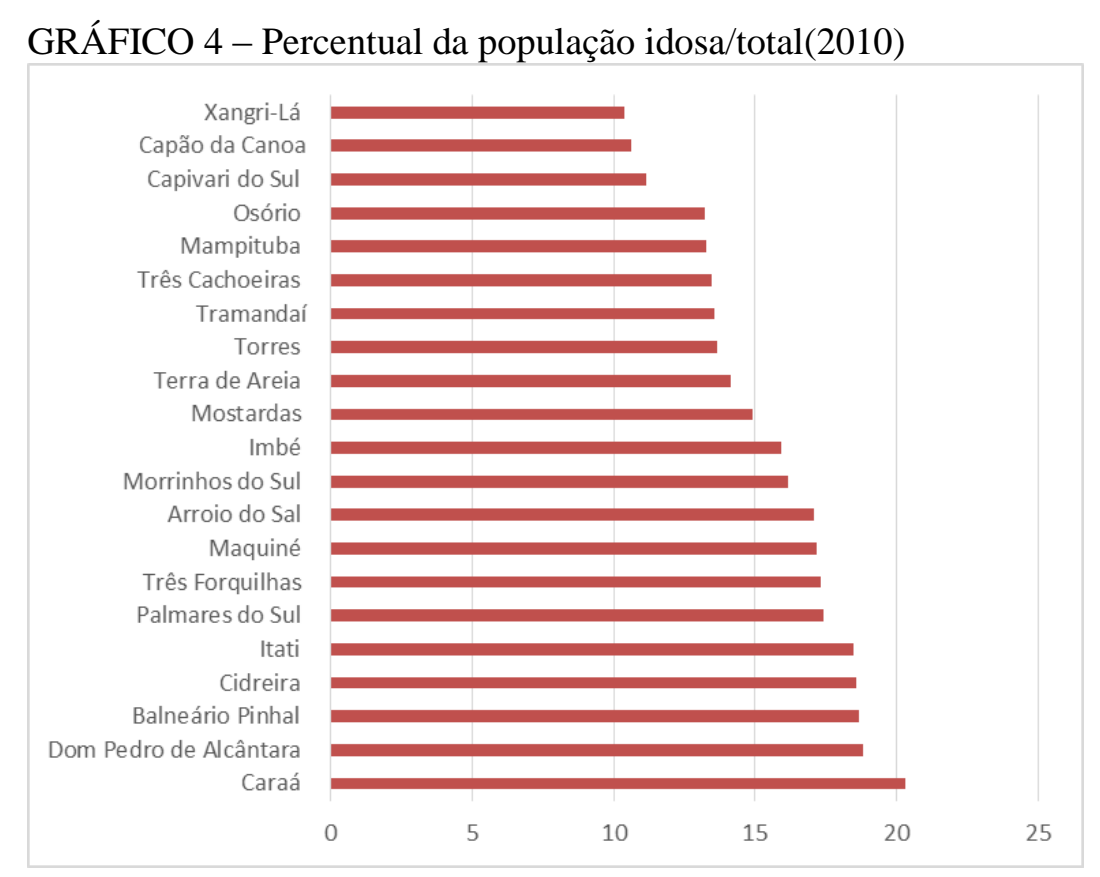

Fonte: IBGE, Elaboração própria

A problemática do envelhecimento do campo não é algo presente somente nos municípios rurais pertencentes ao COREDE Litoral/RS. Bitencourt e Dalto (2015) constataram não apenas o aumento da população idosa, mas também o êxodo rural de jovens na região da AMREC/SC. Este fenômeno foi também problematizado por Silvestro (2001) e Stropasolas (2006) em outras regiões do Estado de Santa Catarina, e por Coradini (2008) que identificou o êxodo rural juvenil no Rio Grande do Sul.

No Brasil, segundo dados do censo, pôde-se observar que entre 2000 e 2010 houve uma redução de $14 \%$ dos residentes rurais com até 39 anos de idade. Entretanto, quando se analisa a população rural de mulheres entre 40 e 54 anos, e homens de 40 a 59 anos, verifica-se um aumento de $4 \%$ para o referido período. E, no que diz respeito a população com idade de aposentadoria rural, entre 2000 e 2010 houve um aumento de $20 \%$. Analisando o COREDE Litoral, verifica-se que para o mesmo período a região apresenta um aumento populacional de $22 \%$, porém quando se observa somente a população rural os dados revelam que houve uma redução de $26 \%$. 
A seguir, o Gráfico 5 apresenta a Taxa de Envelhecimento Humano ${ }^{4}$ para os municípios da região. Esse dado corrobora com os dados dos Censos de 2000 e 2010, uma vez que os municípios rurais se destacam por apresentarem as mais altas taxas, a exemplo de Caraá com 14,4, seguido por Itati com 13 e Dom Pedro de Alcântara com 12,9.

GRÁFICO 5 - Taxa de Envelhecimento (2010)



Fonte: PNUD, Elaboração própria

Após analisar os principais aspectos do envelhecimento populacional do COREDE Litoral/RS, a seguir estão as considerações finais acerca do que foi observado.

\section{CONSIDERAÇÕES FINAIS}

Frente ao objetivo de investigar o processo de envelhecimento populacional nos municípios do Conselho Regional de Desenvolvimento (Corede) do Litoral/RS, constatou-se inicialmente que no período de 2000-2010 esta foi a região do estado com maior destaque no aumento populacional. Com relação à população acima de 60 anos, este aumento foi de $75 \%$ superando as médias estadual e nacional. Os municípios que apresentam a maior população idosa são Tramandaí, Osório, Torres e Capão da Canoa. Todavia dentre os municípios que se destacam pelo aumento desta população no referido período estão Balneário Pinhal, Xangrilá, Imbé, Arroio do Sal e Cidreira. Em contrapartida, Três Cachoeiras, Dom Pedro de Alcântara, Mostardas, Morrinhos do Sul, Mampituba, Maquiné, Três Forquilhas e Palmares do Sul foram

${ }^{4}$ De acordo com o Programa das Nações Unidas para o Desenvolvimento, a Taxa de Envelhecimento Humano é calculada a partir da razão entre a população de 65 anos ou mais de idade e a população total multiplicado por 100. Disponível em: http://www.atlasbrasil.org.br/2013/pt/o_atlas/glossario/ 
os municípios que apresentaram menor crescimento, seguidos por Terra de Areia e Caraá que tiveram redução na população idosa.

Este cenário revela as especificidades de um processo de envelhecimento distinto. Por um lado, tem-se o aumento da população idosa nos balneários proveniente de pessoas que residiam na região metropolitana do estado, e após a aposentadoria buscam um lugar tranquilo que propicie lazer e maior qualidade de vida. Por outro lado, nos municípios rurais verifica-se os fenômenos do êxodo juvenil, da masculinização e do envelhecimento do campo. Ou seja, embora os balneários apresentem expressivo aumento da população idosa por atrair aposentados, os municípios rurais destacam-se pelo intenso processo de envelhecimento daqueles que permanecem no campo.

Em suma, os municípios precisam estar empenhados em atender as deliberações da Política Nacional do Idoso no que se refere à garantia de direitos, à inserção dos idosos no espaço público enquanto sujeitos sociais e coletivos. Porém, os resultados desta pesquisa evidenciam que a população idosa do COREDE Litoral apresenta demandas segundo as especificidades de cada município. O que requer cautela na implementação de políticas públicas, pois estas não podem ser racionalmente planejadas para uma determinada categoria, englobando um universo de indivíduos que na prática não são homogêneos.

Sabemos que o desafio é assegurar a inserção do idoso na sociedade e nos diferentes espaços da esfera pública com garantias de saúde pública, renda, segurança e dignidade. Contudo, este trabalho vem ressaltar que as políticas públicas voltadas à pessoa idosa devem ser pensadas no plural. O que implica assumir a intrínseca heterogeneidade, dadas as diferentes trajetórias de vida, que são determinadas por inserções diferenciadas na vida social e econômica. E tal heterogeneidade revela demandas diferenciadas, o que repercute diretamente na formulação de políticas públicas para o segmento.

\section{REFERÊNCIAS}

BRASIL. Lei n. 8.842, de 04 de janeiro de 1994. Dispõe sobre a Política Nacional do Idoso, cria o Conselho Nacional do Idoso e dá outras providências, Brasília, 1994 Disponível em <http://www.planalto.gov.br/ccivil_03/leis/18842.htm>. Acesso em 30 jul. 2014.

BITENCOURT, Rossandra Oliveira Maciel de; DALTO, Fabiano Abranches Silva. A contribuição da Previdência Social Rural para a redução da desigualdade de renda. Revista de Desenvolvimento Econômico, Salvador, v. 17, n. 2, p.892-914, dez. 2015. 
CAMARANO, A. A. et al. Como vive o idoso brasileiro? In: CAMARANO, A. A. (Org.). Os novos idosos brasileiros: muito além dos 60? Rio de Janeiro: Ipea, 2004. p. 25-73.

COREDE Litoral. Perfil Socioeconômico do COREDE Litoral. Governo do Estado do Rio Grande do Sul, Secretaria do Planejamento, Mobilidade e Desenvolvimento Regional, 2015. Disponível em < http://planejamento.rs.gov.br/upload/arquivos/201512/1513413220151117102724perfis-regionais-2015-litoral.pdf>. Acesso em 03.ago.2018

CORADINI, Lucas. Autonomia e Projetos Profissionais das Jovens na Agricultura Familiar do Rio Grande do Sul. In: BRASIL, Presidência da República. $3^{\circ}$ Prêmio Construindo a Igualdade de Gênero - Redações e artigos científicos vencedores. Brasília: Secretaria Especial de Políticas para as Mulheres. 2008.p.176-188.

FROEHLICH, José Marcos et al . Êxodo seletivo, masculinização e envelhecimento da população rural na região central do RS. Ciência Rural, Santa Maria, v. 41, n. 9, set. p. 16741680. 2011.

FUNDAÇÃO DE ECONOMIA E ESTATÍSTICA. Perfil Socioeconômico COREDEs RS, 2015. Disponível em: <www.fee.rs.gov.br/perfil-socioeconomico/coredes/> Acesso em 03.ago.2018.

IBGE. Banco de Dados Agregados. Censo 2010. Disponível em http://www.sidra.ibge.gov.br/bda/tabela/listabl.asp?c=1552\&z=cd\&o=5. Acesso em: $10 \mathrm{fev}$. 2012.

MACIEL, Rossandra Oliveira. A internalização da Previdência Social Rural em municípios pertencentes à região da AMREC. 2015. 95 f. Dissertação (Mestrado) - Curso de Políticas Públicas, Universidade Federal do Paraná, Curitiba, 2013.

MOTTA, Alda Britto da. As dimensões de gênero e classe social na análise do envelhecimento. Cadernos Pagu, Campinas, n. 13, p.191-221, 1999.

A atualidade do conceito de gerações na pesquisa sobre o

envelhecimento. Sociedade e Estado, vol.25, n.2, p. 225-250, 2010.

UNITED NATIONS. WORLD POPULATION AGEING. NEW YORK, 2015. 164P.

PROGRAMA DA NAÇÕES UNIDAS PARA O DESENVOLVIMENTO. Atlas do

Desenvolvimento Humano, 2013. Disponível em: <http://www.atlasbrasil.org.br/2013/>.

Acesso em: ago.2018

RIO GRANDE DO SUL. Lei n. 10.283, de 17 de outubro de 1994. Dispõe sobre a criação dos Conselhos Regionais de Desenvolvimento - CRDs, Porto Alegre, 1994.

SIQUEIRA, R. L et al. A velhice: algumas considerações teóricas e conceituais. Ciência e Saúde Coletiva, Rio de Janeiro, v. 7, n. 4, p. 899-906, 2002.

SILVA, Marina da Cruz. O processo de envelhecimento no Brasil: desafios e perspectivas. Textos Envelhecimento, Rio de Janeiro, v. 8, n. 1, p. 43-60, 2005. 
SILVESTRO, Milton Luiz et al. Os impasses sociais da sucessão hereditária na agricultura familiar. Florianópolis: EPAGRI; Brasília: Ministério do Desenvolvimento Agrário, 2001.

STROPASOLAS, Valmir Luiz. O mundo rural no horizonte dos jovens. Florianópolis: Ed. da Universidade do Extremo Sul Catarinense, 2006. 346 p. 